\title{
A Amizade Fiel no Sirácida
}

\author{
Nelson Maria Brechó da Silva
}

\section{Resumo}

Este artigo pretende examinar a amizade fiel no Sirácida. Desse modo, analisam-se os temas do amigo fiel, poderosa proteção, tesouro e temor do Senhor. Acrescenta-se, também, o significado do verbo "encontrar" como intimidade e confiança no Senhor. A interpretação do texto permitirá reflexões sobre o sentido maior da amizade à luz da imagem da fidelidade, da poderosa proteção, do tesouro e da sua finalidade ligada ao temor do Senhor.

Palavras-chave: Amizade, Fiel, Tesouro, Temor do Senhor.

\section{Abstract}

This article intends to examine the faithful friendship in Sirach. Thus, we analyze the themes of the faithful friend, powerful protection, treasure and fear of the Lord. It also adds to the meaning of the verb "find" as intimacy and trust in the Lord. The interpretation of the text will allow a greater reflection on the meaning of friendship in the light of the image of fidelity, powerful protection, treasure and its purpose connected with the fear of the Lord.

Keywords: Friendship, Faithful, Treasure, Fear of the Lord. 


\section{Introdução}

Há diversos tipos de amizades nas relações sociais. Contudo, de modo especial na literatura sapiencial, ser amigo fiel implica uma abertura ao outro e que leve ao temor do Senhor. Desse modo, destaca-se nesta reflexão, uma análise sobre o que consiste a amizade no Sirácida. A partir deste pressuposto, num primeiro momento, ilustra-se filologicamente o seu sentido literal, bem como o Sitz-im-Leben, contexto vital da época do autor. No segundo passo, ressalta-se a exegese dos termos "amizade fiel", "tesouro" e o "temor do Senhor" vinculados ao verbo "encontrar". Almeja-se, também, facilitar a sua relação com os demais temas do conjunto do Sirácida e, principalmente com seus interlocutores: Provérbios e Torah. O terceiro momento, por sua vez, caracteriza-se pela pragmática e hermenêutica a fim de salientar a relevância do tema para o mundo helênico-judaico, bem como hoje frente ao contexto de amizade líqui$\mathrm{da}^{1}$, ou seja, consumista. Faz-se mister uma conscientização das pessoas sobre a necessidade de resgatar a experiência de amizades sólidas, ou seja, fieis e pautadas nos encontros que possibilitem o bem recíproco e o temor do Senhor.

\section{Tradução instrumental e segmentação de Sir 6,14.17}

Busca-se, nesse primeiro tópico uma exposição da perícope Sir 6,14.17, bem como seu contexto histórico para situar o Sitz-im-Leben do conceito amizade na literatura sapiencial no Sirácida. Segue-se, abaixo, a versão grega², acompanhada com a tradução instrumental. Além disso, apresenta-se uma proposta de segmentação a fim de facilitar o desenvolvimento exegético.

Eis a versão grega da perícope:

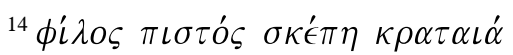

ò $\delta \dot{\epsilon} \epsilon \dot{v} \rho \grave{\omega} \nu \alpha \dot{v} \tau \dot{\tau} \nu \epsilon \hat{v} \rho \epsilon \nu \theta \eta \sigma \alpha \nu \rho o ́ \nu$

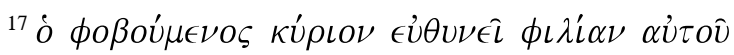

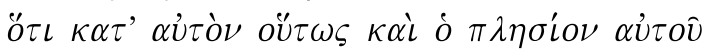

\footnotetext{
${ }^{1}$ Esse conceito da "amizade líquida" corresponde à nossa reflexão pessoal acerca do sociólogo polonês Bauman. Este, por sua vez, fala do "amor líquido". Trata-se, portanto, de uma ideia original nossa, visto que o autor não trata especificamente desse assunto, a saber, amizade. Ver mais detalhes na obra: BAUMAN, Z. Amor líquido. São Paulo: Jorge Zahar, 2004.

${ }^{2}$ RAHLFS, A. Septuaginta: id est vetus testamentum graece iuxta LXX interpretes. 6 ed. Stuttgart: Privilegierte Wurttembergische Bibelanstalt, 1979, v. 2, p. 386.
} 
A tradução instrumental corresponde:

${ }^{14}$ Amigo fiel é poderosa proteção,

E quem o tenha encontrado, encontrou um tesouro.

${ }^{17} \mathrm{O}$ que teme ao Senhor fará correto sua amizade, Pois como ele [Senhor] é, tal será o seu próximo [amigo] ${ }^{3}$.

A segmentação do texto acontece da seguinte maneira:

14 a $\phi^{\prime} \lambda \partial \varsigma \pi \iota \sigma \tau o ́ \varsigma \sigma \kappa \kappa^{\prime} \pi \eta \kappa \rho \alpha \tau \alpha \iota \dot{\alpha}$

a Amigo fiel é poderosa proteção,

${ }^{\mathrm{b}} \dot{o} \delta \epsilon \epsilon \in \dot{U} \rho \hat{U} \nu \alpha \dot{U} \tau \grave{o} \nu \in \hat{U} \rho \epsilon \nu \theta \eta \sigma \alpha \nu \rho o ́ \nu$

${ }^{\mathrm{b}} \mathrm{E}$ quem o tenha encontrado, encontrou um tesouro.

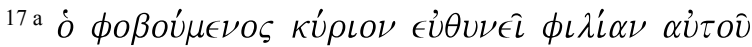

${ }^{a} \mathrm{O}$ que teme ao Senhor fará correto sua amizade,

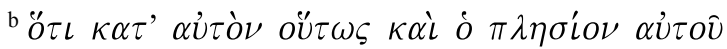

${ }^{\mathrm{b}}$ Pois como ele [Senhor] é, tal será o seu próximo [amigo].

\section{Crítica textual}

A perícope de Sirácida apresenta uma variante referente ao v. 17. O vocábulo фoßoú $\mu \in \nu o \varsigma$ no Codex Sinaiticus, representado pela letra (S), ao invés do singular, utiliza o plural фoßoú $\mu \in \nu$ o . Contudo, para o presente estudo, opta-se pelo singular proposto pelo texto de Rahlfs, que remete ao séc. II a.C., ao passo que o (S) pertence ao séc. IV e V d.C. ${ }^{4}$. O critério pela aceitação do primeiro corresponde pelo fato de ser mais antigo do que o segundo.

\footnotetext{
${ }^{3}$ Tradução literal do grego e consultada na BÍBLIA de Jerusalém. 7 ed. São Paulo: Paulus, 2008, pp. 1151-1152.

${ }^{4}$ Conforme a nota de rodapé da edição crítica de: RAHLFS, A. Septuaginta: id est vetus testamentum graece iuxta LXX interpretes. 6 ed. Stuttgart: Privilegierte Wurttembergische Bibelanstalt, 1979, v. 2, p. 386.
} 


\section{Delimitação}

No tocante à delimitação ${ }^{5}$, A perícope de Sir 6,14.17 tem início com a mudança de tema no v. 14. Os versículos anteriores tratam de vários tipos de

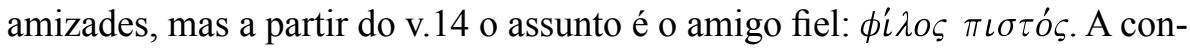
clusão, encontra-se no v.17, visto que relaciona a amizade à pessoa temente

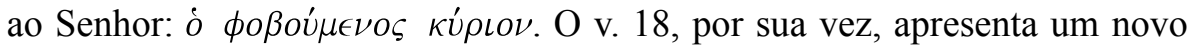
assunto demarcado pelo vocativo: $\tau$ '́ $\kappa \nu o \nu$ (filho) seguido por uma exortação sobre como adquirir a sabedoria.

A estrutura da perícope se apresenta da seguinte forma: localiza-se no capítulo 6 e é, indubitavelmente, o relato de Sirácida mais relevante a propósito da amizade. Os v. 5-17 ilustram um ensinamento de como discernir se uma amizade é, de fato, fiel ou de mero interesse. Vale dizer que a perícope anterior comenta sobre o orgulho (v.2-4), enquanto que a posterior (v.18-23) frisa a aquisição da sabedoria. Diante disso, os v.14 e 17 apontam o sentido da amizade ligada à fidelidade e ao temor do Senhor. Contudo, para sua maior compreensão, analisa-se o conjunto dos v.5-17. Segundo Krinetzski, estudioso sobre o Sirácida, a estrutura literária de Sir 6,6-17 se divide em três partes: "v.5-6 - Amigo e confidente [conselheiro]; v.7-13 - Comportamento frente ao amigo em geral; v.14-17b - O verdadeiro amigo e o seu valor" ${ }^{\text {. }}$. A proposta do estudioso abarca vários pontos interessantes, tais como a referência dos amigos em geral e do amigo verdadeiro. No entanto, ao ver a passagem do v.17, faz-se importante considerar o papel do temor do Senhor, pois este tem suma importância para uma correta amizade. Aqui se encontra uma diferença fundamental com a filosofia aristotélica, pois esta trata da $\tau \in \lambda \in \iota \alpha$ d $\iota^{\prime} \iota \alpha$, amizade perfeita, a partir do bem e da reciprocidade, de modo que a pessoa se torna, realmente, virtuosa. Segundo Aristóteles, "a forma mais perfeita da amizade é aquela entre os indivíduos bons e mutuamente semelhantes em matéria de virtude. Isto porque esses amigos se desejam igualmente o bem alheio na qualidade de bem e são bons em si mesmos"?.

\footnotetext{
${ }^{5}$ A delimitação da perícope "deseja indicar os caminhos que convém tomar para chegar a uma interpretação da Bíblia que seja tão fiel quanto possível a seu caráter ao mesmo tempo humano e divino". PONTIFÍCIA COMISSÃO BÍBLICA. A interpretação da Bíblia na Igreja. São Paulo; Loyola, 1994, p. 13.

6 "v.5-6 - Freund und Vertrauter; v.7-13 - Verhalten gegenüber den Freuden im allgemeinen; v.14-17b - Der treue Freund und sein Wert". KRINETZSKI, P. G. Die Freundschaftsperikope Sir 6,5-17 in traditionsgeschichtlicher Sicht. Biblische Zeitschift (1979) pp. 214-215.

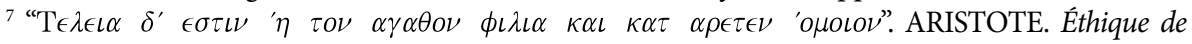




\section{Contexto histórico}

A redação final do Sirácida se situa aproximadamente entre 190 e 180 a. C. com os generais de Alexandre Magno: Ptolomeus Lágidas com o Egito e a Palestina e os Selêucidas com a Síria. Contudo, a Palestina passou aos Selêucidas com Antíoco III, de modo que se incrementa a sua helenização, o que caracteriza um período de "inverno" se for comparar com a situação anterior dos Ptolomeus, no qual a Palestina, principalmente a Judeia tinha certo privilégio de autonomia, sobretudo, na figura do sumo sacerdote Simão II, em 195 a. C. período denominado como "Primavera" da identidade judaica (cf. Eclo 50). Mais adiante, segundo Storniolo, "na história nascerá a revolta dos Macabeus, 167 a 164 a. C." .

\section{Gênero literário}

Quanto ao gênero literário da tradição sapiencial do Sirácida, segundo Cássio Silva é masal que significa: provérbio breve. Nesse sentido, "trata-se de um ensinamento formulado em duas ou três linhas (chamadas membros), com diversas finalidades: formação, sátira, sarcasmo, crítica, ameaça etc. Os membros do masal normalmente seguem um tipo de paralelismo: sinonímico, antitético

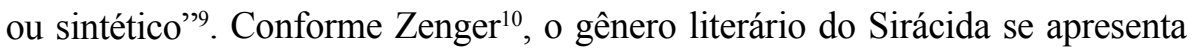
como ditado popular a partir do pressuposto das experiências cotidianas.

De acordo com Gilbert ${ }^{11}$, o papel do mestre envolve a formação dos

Nicomaque. Paris: Garnier Frères, 1940, p. 359 [livro VIII, 3].

${ }^{8}$ STORNIOLO, I. O livro do Eclesiástico: a identidade de um povo. São Paulo: Paulus, 1994, p. 9.

${ }^{9}$ SILVA, C. M. D. Leia a bíblia como literatura. São Paulo: Loyola, 2007, p.58.

${ }^{10} \mathrm{O}$ ditado popular formula, "muitas vezes de maneira figurada e drástica, a experiência de vida do povo. O ditado tem uma visão panorâmica de muitas experiências semelhantes e as condensa, quase como uma soma, num breve provérbio. Embora sua intenção seja didática, o ditado não formula o ensinamento expressamente, porém deixa por conta do ouvinte que tire pessoalmente do ditado as consequências práticas. Quase sempre o ditado é de uma linha só, mas também pode ocorrer como provérbio de duas linhas. $\mathrm{O}$ ditado aborda experiências do âmbito da vida cotidiana. Entretanto, também serve para interpretar, com realce súbito, situações políticas". ZENGER, E. Peculiaridade e importância da sabedoria em Israel. In:

Introdução ao Antigo Testamento. São Paulo: Loyola, 2003, p. 288.

11 "Como todo mestre de sabedoria, Ben Sirac formava jovens de famílias abastadas e os preparava para a vida; eles deviam assumir mais tarde responsabilidades sociais. Não se estranhe, por isso, que se encontrem em seu livro muitas reflexões e conselhos sobre o comportamento em sociedade e o trato social". GILBERT, M. O ensinamento dos sábios. In: MONLOBOU, L. [et Al.]. Os salmos e os outros escritos. São Paulo: Paulus, 1996, p. 366. 
jovens para a vida. Por essa razão, Sirácida utiliza as experiências do cotidiano a fim de guiar as pessoas à aplicação da Lei. Trata-se, portanto, da prática dos mandamentos, com a qual se torna possível a propagação dos valores essenciais à fé, tais como a constância e a fidelidade por meio do temor ao Senhor ${ }^{12}$, a fim de que a amizade seja, de fato, correta.

\section{Pragmática}

Sirácida deseja salvaguardar o apreço pela Lei, proveniente do pensamento hebraico que é concreto e simbólico; com a sabedoria e o temor do Senhor situado na reflexão grega que é abstrata e especulativa. Nesse sentido, Frei Gilberto Gorgulho postula o papel do temor do Senhor e da sabedoria ${ }^{13}$.

Gorgulho realça o aspecto da sabedoria e da Lei vinculadas à fonte de vida. Isso leva a pensar e a ver que Sirácida almeja fornecer ensinamentos do cotidiano que possibilitem ao melhor seguimento do Senhor por meio de amizades fieis aliadas pela possibilidade de vivenciarem o temor do senhor (cf. Sir 6,17b) e de verem nelas a imagem do tesouro e da preciosidade. Conforme Romi Auth, a sabedoria se junta com a Lei no Sirácida ${ }^{14}$.

Para Auth, o pensamento de Sirácida trata de uma interpretação da Lei à luz da cultura grega. Percebe-se, dessa forma, a preocupação do Sirácida

\footnotetext{
${ }^{12} \mathrm{Na}$ vivência do temor, segundo Gilbert, a pessoa se abre para o mestre que é fonte de toda a sabedoria, o Senhor. Eis a chave central para a compreensão do temor no Sirácida, a sabedoria. "Les deux premiers chapitres servent d’entrée en matière. Le Seigneur est la source de toute sagesse et Il ne la révèle à profusion quà sés fidèles, qui le craignent ou qui laiment (Si 1,1-10). La crainte du Seigneur, ouverture aimante et humble au Seigneur, comble de bénédictions (Si 1,10-20). On trouve ainsi dès le début les clés de toute l'oeuvre du maître". Itálico nosso. GILBERT, M. À lécole de la sagesse. La pédagogie des sages dans lancien Israël. Gregorianum 85, 1 (2004) p. 33.

13 "a narrativa da história é afirmação da tradição da cultura grega com seus herois e deuses, principalmente Júpiter Olímpico, que procura sobrepor-se a Iahweh. O autor procura salvar a tradição do povo de Deus fazendo a afirmação de que a sabedoria é a Lei (Eclo 24), fonte de vida e de liberdade para o Povo de Deus. Subjetivamente, a sabedoria é o temor de Deus e, objetivamente, ela é a Lei, a norma de Vida que dá identidade e salva o Povo de Deus: Toda a Sabedoria é o Temor de Iahweh, e em toda a Sabedoria há a prática da Lei (Eclo 19,20). Assim, o Temor de Iahweh, a Lei e a Memória dos Pais explicam a estrutura do livro e o dinamismo da longa exposição". GORGULHO, G. A palavra dos sábios. In: VV. AA. A história da palavra. São Paulo: Siquem-Paulinas, 2003, v. 1, p. 151. ${ }^{14}$ Para o autor [Sirácida] não há dúvidas que a sabedoria identifica-se com a Torá, com a revelação bíblica. Ele trata de legitimar e interpretar a lei, mas numa perspectiva sapiencial. Em si mesma ela não é objeto de interesse especial e sim como um elemento na grande temática sapiencial. Aqui parece residir a originalidade do autor no confronto com os demais escritos sapienciais. Ele encontrou uma forma de relacionar o tema da lei, que é central no judaísmo, com o tema da sabedoria, forte na cultura grega. AUTH, R. Deslizes do Sirácida. Estudos Bíblicos, 48 (1996) pp. 45-46.
} 
em transmitir um ensinamento com credibilidade. No entanto, a autora não analisa uma categoria importante: a experiência comunitária. Aquela pessoa que vive a verdadeira amizade, com efeito, ela teme ao Senhor, porque vê no encontro com o amigo a Sua presença ${ }^{15}$. O Senhor coloca uma ordem no mundo e o ser humano faz reverência, ou seja, enamora-se pelo Senhor, de modo que ordena a vida ao Seu querer. O grande esforço do sábio se faz no descobrir a ordem. Parte-se, portanto, da experiência comunitária da amizade para se chegar à Lei.

\section{Hermenêutica}

A amizade é uma experiência gratificante e dolorosa. É na desgraça que a verdadeira amizade se manifesta (Sir 6,8-12); até passar por tal prova, não se saberá quem é o fi,loj pisto,j, amigo fiel (Sir 40,23a). Este corresponde ao companheirismo que implica uma relação mútua. Caso contrário, o amigo se torna de ocasião, porque não persevera e pode virar inimigo. Por isso, segundo Líndez, "vale a pena a tentativa de formar uma amizade"16.

Conforme Bauman, "a modernidade começa quando o espaço e o tempo são separados da prática da vida e entre si, e assim podem ser teorizados como categorias distintas e mutuamente independentes da estratégia e da ação"17. Assim, o tempo tem história. Vivencia-se, hoje, a era do espaço virtual, no qual a informação corre veloz, independente de um espaço físico e sim virtual. Por essa razão, as amizades se tornam líquidas, de modo que o tempo se esvai e sem a ligação com o espaço. Como tecer amizades que sejam sólidas diante do universo líquido? Quiçá seja pela busca de alguns elementos sapienciais a fim de possibilitar novos horizontes acerca da amizade.

\section{Conclusão}

Ao comentar sobre a situação atual, Libanio sublinha a cultura da velocidade $^{18}$. Percebe-se o desafio eclesial, a saber, um diálogo entre os

\footnotetext{
${ }^{15} \mathrm{O}$ encontro tem como finalidade o temor do Senhor, por meio da confiança recíproca no desejo de, segundo Di Lella, guardar os mandamentos da Torah: "Ben Sira teaches that believers must love and fear God, must walk in his ways and keep the commandments od the law". DI LELLA, A. The teaching of Ben Sira. The Anchor Bible, 39 (1987) p. 79.

${ }^{16}$ LÍNDEZ, J. V. Sabedoria e sábios em Israel. São Paulo: Loyola, 1999, p. 122.

${ }^{17}$ BAUMAN, Z. Modernidade líquida. Rio de Janeiro: Jorge Zahar, 2001, p. 15.

18 “o Concílio Vaticano II está aí diante de nós em seus textos, nos relatos dos que o viveram, nos
} 
escritos do Vaticano II com os anseios de uma teologia que leve em conta o enamoramento por Deus mediante a constância apresentadas pelas diversas fragmentações do saber e dos sentimentos. Sirácida soube dialogar com o seu tempo. Por conseguinte, faz-se indispensável o desenvolvimento de pequenas comunidades que pensem, vivem e partilhem os seus dons, num exercício da reciprocidade frente às provações preconizadas pelo individualismo. Aliás, Libanio cita uma célebre frase de Yves Congar: "Tudo se modifica sem cessar. Existem, porém, continuidades profundas"19. A riqueza da Bíblia, portanto, encontra-se na sua compreensão do contexto vital e atualização de acordo com a comunidade local atual.

\section{Referências Bibliográficas}

ARISTOTE. Éthique de Nicomaque, Paris, Garnier Frères. 1940. [livro VIII, 3].

AUTH, R. Deslizes do Sirácida. Estudos Bíblicos, 48, 1996, pp. 43-48.

BAUMAN, Z.. Modernidade líquida. Rio de Janeiro: Jorge Zahar, 2001.

BÍBLIA de Jerusalém. 7 ed., São Paulo: Paulus, 2008.

DI LELLA, A. The teaching of Ben Sira. The Anchor Bible, 39 (1987) pp. 75-127.

GILBERT, M. À l'école de la sagesse. La pédagogie des sages dans l'ancien Israël. Gregorianum, 85, 1 (2004) pp. 20-42.

. O ensinamento dos sábios. In: MONLOBOU, L. [et Al.]. Os salmos e os outros escritos. São Paulo: Paulus, 1996.

GORGULHO, G. A palavra dos sábios. In: VV. AA. A história da palavra. São Paulo: Siquem-Paulinas, 2003. v. 1. pp. 133-154.

KRINETZSKI, P. G. Die Freundschaftsperikope Sir 6,5-17 in Traditionsgeschichtlicher Sicht, Biblische Zeitschift (1979) pp. 212-233. LIBANIO, J. B. Vaticano II: em busca de uma primeira compreensão. São Paulo: Loyola, 2005.

LÍNDEZ, J. V. Sabedoria e sábios em Israel. São Paulo: Loyola, 1999.

MINISSALE, A. Sirácida: as raízes na tradição. São Paulo: Paulinas, 1993.

estudos interpretativos como um desafio eclesial. Para a história, quarenta anos são um período muito curto, mas para a cultura da velocidade, da internet, do on line, do descartável, o Concílio parece perdido nas blumas de um longínquo passado". LIBANIO, J. B. Vaticano II: em busca de uma primeira compreensão. São Paulo: Loyola, 2005, p. 215.

${ }^{19}$ LIBANIO, J. B. Vaticano II: em busca de uma primeira compreensão. São Paulo: Loyola, 2005, p. 205. 
PONTIFÍCIA COMISSÃO BÍBLICA. A interpretação da Bíblia na Igreja. São Paulo; Loyola, 1994.

RAHLFS, A. Septuaginta: id est vetus testamentum graece iuxta LXX interpretes. 6 ed., Stuttgart, Privilegierte Wurttembergische Bibelanstalt. 1979, v. 2.

SILVA, C. M. D. Leia a bíblia como literatura. São Paulo: Loyola, 2007.

STORNIOLO, I. 1994. O livro do Eclesiástico: a identidade de um povo, São Paulo, Paulus.

Nelson Maria Brechó da Silva Mestre em Filosofia pela UNESP de Marília-SP Mestrando em Teologia pela PUC - SP E-mail: nelsonbrecho@yahoo.com.br

Artigo Recebido em 22/08/2011 Artigo Aprovado em 21/11/2011 